\title{
Hemoptizi Yakınması ile Başvuran Hastalarda Etyolojik Değerlendirme
}

\author{
Etiological Evaluation in Patients Presenting with Hemoptysis \\ Mustafa Çolak ${ }^{1}$, Mehmet Ali Aslaner ${ }^{2}$ \\ ${ }^{1}$ Nevşehir Devlet Hastanesi Göğüs Hastalıkları Kliniği \\ ${ }^{2}$ Nevşehir Devlet Hastanesi Acil Tip Kliniği \\ Yazıșma Adresi / Correspondence: \\ Mustafa Çolak \\ Nevșehir Devlet Hastanesi Ragıp Üner Mahallesi, 50130 Nar Belediyesi/Nevșehir Merkez/Nevşehir \\ T: +905326803961 E-mail : drmclk@yahoo.com \\ Geliş Tarihi / Received : 12.05.2019 Kabul Tarihi / Accepted : 04.10.2019 \\ Orcid : \\ Mustafa Çolak https://orcid.org/: 0000-0001-8310-3766 \\ Mehmet Ali Aslaner https://orcid.org/0000-0002-7851-7881 \\ ( Sakarya Tip Dergisi / Sakarya Med J 2019, 9(4):626-631 ) DOI: 10.31832/smj.563499
}

\footnotetext{
$\ddot{O} z$

Amaç Hemoptizi yakınması ile Göğüs Hastalıkları polikliniği ve Acil polikliniğine başvuran hastalarda altta yatan etiyolojik faktörlerin dağılımını değerlendirmek

Gereç ve $\quad$ 01.01.2018 / 30.06.2018 tarihleri arasında hastanemize hemoptizi yakınması ile başvuran 101 hastanın kayıtları retrospektif olarak incelendi.

Yöntemler

Bulgular Kayıtları incelenen 101 hastanın \%50,50’si ( $\mathrm{n}=51$ ) kadın, \%49,50’si ( $\mathrm{n}=50$ ) erkek idi. Hastaların ortanca yaşı 51 (IQR 34-64) saptandı. Hemoptizi miktarına göre değerlendirildiğinde 99 hastada minör hemoptizi gözlenmiș olup, 2 hastada masif hemoptizi görülmüștür. Hastaların akciğer grafilerinde en sık gözlenen patolojik bulgular; infiltrasyon $(\% 22,77)$, KOAH $(\% 7,92)$ ve bronșektazi $(\% 6,93)$ idi. Toraks bilgisayarlı tomografilerinde en sik gözlenen patolojik bulgular ise infiltrasyon (\%21,73), bronșektazi $(\% 10,14)$ ve pulmoner tromboemboli $(\% 8,69)$ idi. Tanısal değerlendirme amaçlı $16(\% 17,80)$ hastaya fiberoptik bronkoskopi uygulandı. 9 hastada kanama odağı saptanırken, 7 hastada kanama bulgusuna rastlanılmadı. Hastalarda saptanan en sık hemoptizi nedenleri; akut bronşit (\%36,63), idiyopatik hemoptizi (\%21,78) ve pnömoni $(\% 20,79)$ idi. Göğüs Hastalıkları polikliniğine başvuran hastalarda akut bronşit, idiyopatik hemoptizi ve pnömoni daha sık izlenirken, Acil polikliniği başvurularında bronşektazi ve pulmoner tromboemboli tanılarının daha sık izlendiği görüldü.

Sonuç İkinci basamak sağlık kuruluşlarına hemoptizi yakınması ile başvurularda olguların çoğunluğunu enfeksiyöz nedenler ve idiyopatik hemoptizi oluşturmaktadır. Zaman içerisinde hemoptizi etiyolojisinde yer alan hastalıkların sıklığında değişiklik gözlenmiş ve daha benign hastalıklara bağlı oluşan hemoptiziler ön plana çıkmıștır

Anahtar Hemoptizi; etiyoloji; poliklinik başvurusu

kelimeler

Abstract

Objective The aim of study is to evaluate the distribution of the underlying etiologic factors in patients admitted to the Chest Diseases outpatient clinic and emergency department with the complaint of hemoptysis.

Materials 101 patients, who were admitted to our hospital for hemoptysis between 01.01.2018 / 30.06.2018, were retrospectively reviewed. and Methods

Results Of the 101 patients whose records were examined, $\% 50,50$ ( $n=51)$ were female and $\% 49,50$ ( $n=50)$ were male. The median age of the patients was 51 (IQR 34-64). According to the amount of hemoptysis, 99 patients had minor hemoptysis and 2 patients had massive hemoptysis. The most common pathological findings in patients with chest radiographs; infiltration (\%22,77), COPD $(\% 7,92)$ and bronchiectasis $(\% 6,93)$. The most common pathological findings in thorax computed tomography were infiltration $(\% 21,73)$, bronchiectasis $(\% 10,14)$ and pulmonary thromboembolism $(\% 8,69)$. Fiberoptic bronchoscopy was performed in $16(\% 17,80)$ patients for diagnostic evaluation. Bleeding was detected in 9 patients and no bleeding was observed in 7 patients. The most common causes of hemoptysis in patients were; acute bronchitis, idiopathic hemoptysis and pneumonia. Acute bronchitis (\%36,63), idiopathic hemoptysis (\%21,78) and pneumonia $(\% 20,79)$ were more common in the patients admitted to the Chest Diseases outpatient clinic; however, bronchiectasis and pulmonary thromboembolism diagnoses were more frequent in emergency polyclinic applications.

Conclusion The majority of the cases with infectious causes and idiopathic hemoptysis are present in the second step health institutions with complaints of hemoptysis. There was a change in the frequency of diseases in the etiology of hemoptysis and haemoptysis due to more benign diseases was come into prominence.

Key words hemoptysis; etiology; outpatient application
} 


\section{GIIRIŞ}

Hemoptizi alt solunum yollarında oluşan kanamaya ikincil kan ekspektorasyonu olarak tanımlanır. Klinik pratikte hemoptizi yakından takip edilmesi gereken yaygın bir semptomdur. ${ }^{1}$ Gögüs hastalıkları polikliniklerine başvuran hastaların \%6-8'inden, göğüs hastalıkları servislerine yatışların \%11'inden hemoptizi sorumlu tutulmaktadır. ${ }^{2}$ Hemoptizi kaynağı pulmoner veya bronşiyal dolaşımdır. Akciğere gelen kanın \%95’i pulmoner arter, \%5’i bronşiyal arter kökenlidir. Bronşiyal arterler aorta ve internal torasik arterden köken alır. Hemoptizilerde kaynak sıklıkla bronşiyal arterlerdir. ${ }^{2}$ Tanımlamada farklılıklar olmakla birlikte, genellikle günde $600 \mathrm{ml}$ ve üzeri kanamalar masif hemoptizi olarak kabul edilmektedir. Ancak, masif hemoptiziyi tanımlamak için literaturde 100 ile $1000 \mathrm{ml}$ arasında değișen farklı rakamların verildiğinin de vurgulanması gerekmektedir. ${ }^{3-5}$

Hemoptizi hastalarının çoğunluğu minör hemoptizi düzeyinde iken, \%5'den azı hayatı tehdit eden ve acil müdahale gerektirecek kadar şiddetli olan masif hemoptizi düzeyindedir. $^{6}$

Hemoptizinin öncelikli olarak akut ve kronik bronşit, pnömoni, tüberküloz, akciğer absesi, bronşektazi ve akciğer kanseri gibi yaygın sebepleri vardır. Enfeksiyonlar hemoptizilerin yaklaşık olarak \%60-70'lik kısmını oluşturan en yaygın nedendir. ${ }^{7}$ Amerika'da yapılan bir çalışmada tüm hemoptizi olgularının \%26’sını bronşitler, \%10’unu pnömoniler ve \%8'ini de tüberkülozların oluşturduğu belirtilmiştir. ${ }^{8}$ Primer akciğer kanserlerinin Amerika'da hemoptizilerin \%23'ünün nedeni olduğu ifade edilmektedir. Bronkojenik karsinomlar hemoptiziden sorumlu akciğer kanserinin \%5-44'ünü oluştururlar. ${ }^{9}$ İdiyopatik hemoptizi bir dışlama tanısıdır. Hastaların \%7-34'ünde çok dikkatli bir çalışmaya rağmen hemoptizi sebebi tanımlanamamaktadir. $^{10}$

Çalışmamızda 01.01.2018 / 30.06.2018 tarihleri arasında, ikinci basamak devlet hastanesinin Göğüs Hastalıkları polikliniği ve Acil polikliniğine hemoptizi yakınması ile başvuran hastalarda altta yatan etiyolojik faktörleri değerlendirmeyi amaçladık.

\section{GEREÇ ve YÖNTEMLER}

Çalışmamızda 01.01.2018 / 30.06.2018 tarihleri arasında Nevşehir Devlet Hastanesi Göğüs Hastalıkları polikliniği ve Acil polikliniğine hemoptizi yakınması ile başvuran 101 hasta retrospektif olarak değerlendirildi. 16 yaş üstü hastalar çalışmaya kabul edildi. Olguların tekrarlayan başvuruları çalışmaya kabul edilmedi. İlaç kullanımına bağlı hemoptiziler, bulantı-kusma ile beraber olan kanamalar, trombositopeniye bağlı kanamalar çalışmaya alınmadı. Hastalara ait demografik veriler, kronik akciğer hastalığı öyküsü, eşlik eden ek hastalıklar ve radyolojik bulguları on-line kayıt sistemi üzerinde taranarak kayıt altında alınd1. Tanı aşamasında hastalara sırasıyla endikasyon dahilinde akciğer grafisi, toraks bilgisayarlı tomografi (BT) ve fiberoptik bronkoskopi işlemleri uygulanmıştır. Çalışma için Nevşehir Hacı Bektaş Veli Üniversitesi Etik Kurulu’ndan onam alındı. Tüm veriler SPSS programına yüklenerek ortalama ve yüzdeler hesaplandi.

İstatistiksel analiz IBM SPSS Statistics for Windows, Versiyon 21 ve MedCalc ${ }^{\oplus}$ Versiyon 15.8 kullanılarak gerçekleştirildi. Sürekli veriler ortanca ve çeyrek aralıklar (IQR) olarak belirtildi. Kategorik veriler frekans ve yüzdeler olarak belirtildi. İki grup arasındaki normallik analizi Shapiro-Wilk analizi ile yapıldı. Sürekli veriler içeren ikili gruplar arasındaki fark Mann-Whitney testi ile bakıldı. Kategorik veriler Pearson's $\chi^{2}$ veya Fisher's exact testi ile karşılaştırıldı. Kritik a değeri 0,05 olduğunda anlamlı kabul edildi.

\section{BULGULAR}

Çalışma dönemi içerisinde hastanemize hemoptizi yakınması ile başvuran hastaların kayıtları tarandığında, değerlendirilen 101 olgunun (74 olgu Göğüs Hastalıkları polikliniği başvurusu, 27 olgu Acil polikliniği başvurusu) ortanca yaşı 51 (IQR 34-64) idi ve kadın cinsiyet tüm 
olguların \%50,50 ( $\mathrm{n}=51)^{\prime}$ 'sini oluşturdu. Yaş gruplarına bakıldığında 16-29 yaş grubu \%19,80 oranında, 30-44 yaş grubu $\% 18,80,45-59$ yaş grubu $\% 29,70$ ve $\geq 60$ yaş grubu $\% 31,70$ oranında olduğu görüldü.

Hastaların özgeçmişine bakıldığında tüm olguların \%30,70 (n=31)'inde kronik akciğer hastalığ1 öyküsü olduğu görüldü; bu olguların 13'ünde kronik obstruktif akciğer hastalığı (KOAH), 11'inde bronşektazi, 5'inde astım ve 2 olguda akciğer kanseri öyküsü vardı. Akciğer dışı ek hastalık öyküsünün ise tüm hastaların \%59,40’ında mevcut olduğu görüldü. Bu hastalarda görülen ek hastalıklar sıklık sırasıyla; 32 hastada kardiyovasküler hastalık (\%31,50), 11 hastada gastrointestinal sistem hastalığ ${ }_{1}(\% 10,80), 10$ hastada psikiyatrik hastalık $(\% 9,90), 9$ hastada endokrin sistem hastalığ $1(\% 8,90), 6$ hastada karaciğer hastalığ $(\% 5,90), 5$ hastada böbrek yetmezliği $(\% 4,90), 4$ hastada otoimmun hastalık $(\% 3,90), 2$ hastada malignite $(\% 1,90)$, 2 hastada nörolojik hastalık (\%1,90), 2 hastada obstruktif uyku apne sendromu $(\% 1,90)$ olduğu saptanmıştır.

Tüm hastaların başvurularında akciğer grafileri görülmüş olup; elli dokuz hastanın grafisi normal saptanırken, yirmi üç hastada infiltrasyon, yedi hastada bronşektazi, sekiz hastada KOAH ile uyumlu bulgular, dört hastada kitle saptanmıştır. Tüm hastalar içinde altmış dokuz $(\% 68,30)$ hastanın toraks BT'si değerlendirildi. Değerlendirme sonucunda yirmi dokuz hastada normal bulgular ile sonuçlanırken, on beş hastada pnömoni, yedi hastada bronşektazi, altı hastada pulmoner tromboemboli, dört hastada kitle, dört hastada buzlu cam görünümü, dört hastada amfizem, bir hastada pulmoner alveoler hemoraji ile uyumlu bulgular saptandı. Çalışmaya alınan hastaların akciğer grafilerinde en sık gözlenen patolojik bulgular; infiltrasyon $(\% 22,77)$, KOAH $(\% 7,92)$ ve bronşektazi $(\% 6,93)$ idi. Hastaların toraks BT'lerinde en sık gözlenen patolojik bulgular; infiltrasyon $(\% 21,73)$, bronşektazi $(\% 10,14)$ ve pulmoner tromboemboli $(\% 8,69)$ idi (Tablo 1$)$.

\begin{tabular}{|c|c|c|}
\hline Radyolojik bulgular & $\begin{array}{l}\text { Akciğer grafisi } \\
\text { n (\%) }\end{array}$ & $\begin{array}{c}\text { Toraks BT } \\
\mathrm{n}(\%)\end{array}$ \\
\hline İnfiltrasyon & $23(22,77)$ & $15(21,73)$ \\
\hline Bronşektazi & $7(6,93)$ & $7(10,14)$ \\
\hline Pulmoner tromboemboli & $0(0)$ & $6(8,69)$ \\
\hline Kitle & $4(3,96)$ & $4(5,79)$ \\
\hline КОАН & $8(7,92)$ & $4(5,79)$ \\
\hline Buzlu cam alanları & $0(0)$ & $4(5,79)$ \\
\hline Olağan & $59(58,41)$ & $29(42,02)$ \\
\hline
\end{tabular}

Tanısal değerlendirme amaçlı $16(\% 17,80)$ hastaya fiberoptik bronkoskopi uygulandı. Bu hastalara akciğerde kitle, tedaviye rağmen devam eden alt solunum yolu enfeksiyonu ile beraber hemoptizi olması, pulmoner alveoler hemoraji, tüm değerlendirmelere ve semptomatik tedaviye rağmen sebebi bulunamayan ve devam eden hemoptizi nedenli fiberoptik bronkoskopi uygulanmış olup, dokuz hastada kanama odağı (enfeksiyona sekonder, tümör, pulmoner alveoler hemoraji) saptanırken, yedi hastada kanama bulgusuna rastlanılmadı. Hastaların başvurduğu poliklinik ile fiberoptik bronkoskopi uygulanması açısından değerlendirildiğinde, aradaki fark istatistiksel olarak anlamlı bulanmamıștır; $p=0,547$. Hastaların tanıları incelendiğinde en sık akut bronşit $(\% 36,63)$, idiyopatik hemoptizi $(\% 21,78)$ ve pnömoni $(\% 20,79)$ saptandı (Tablo 2$)$.

\begin{tabular}{|l|c|}
\hline \multicolumn{2}{|l|}{ Tablo 2. Hemoptizi ile başvuran hastaların tanıları } \\
\hline Öntanılar & $\mathrm{n}(\%)$ \\
\hline Akut bronşit & $37(36,63)$ \\
\hline İdiyopatik hemoptizi & $22(21,78)$ \\
\hline Pnömoni & $21(20,79)$ \\
\hline Bronşektazi & $7(6,93)$ \\
\hline Pulmoner emboli & $6(5,94)$ \\
\hline Akciğer kanseri & $4(3,96)$ \\
\hline KOAH alevlenme & $3(2,97)$ \\
\hline Pulmoner alveolar hemoraji & $1(0,99)$ \\
\hline KOAH, kronik obstruktif akciğer hastalı̆̆1 & \\
\hline
\end{tabular}


Hemoptizi nedenli yapılan başvuruların \%71,28'i Göğüs Hastalıkları polikliniğine , \%28,72'si Acil polikliniğine ait idi. Acil polikliniğine başvuran hastaların ortanca yaşı, Göğüs Hastalıkları polikliniğine başvuran hastalardan daha yüksekti (sırasıyla; 57 [IQR 43-72), 47 [IQR 31-60], $\mathrm{p}<0,013)$. Hastaların başvuru polikliniği ile hemoptizi etiyolojisinde yer alan hastalıkların sıklığı açısından değerlendirildiğinde, aradaki fark istatistiksel olarak anlamlı bulunmamıștır; $\mathrm{p}=0,063$ (Tablo 3).

\begin{tabular}{|c|c|c|c|}
\hline \multicolumn{4}{|c|}{$\begin{array}{l}\text { Tablo 3. Poliklinik ve acil servise hemoptizi ile başvuran } \\
\text { hastaların analizi }\end{array}$} \\
\hline & $\begin{array}{c}\text { Poliklinik } \\
\mathrm{n}=72\end{array}$ & $\begin{array}{c}\text { Acil servis } \\
\mathrm{n}=29\end{array}$ & $\mathrm{P}$ \\
\hline Yaş, median (IQR) & $47(31-60)$ & $57(43-72)$ & 0,013 \\
\hline Cinsiyet, kadın & 38 & 13 & 0,470 \\
\hline $\begin{array}{l}\text { Kronik akciğer hast- } \\
\text { alığı öyküsü, } \mathrm{n}(\%)\end{array}$ & $20(27,77)$ & $11(37,93)$ & 0,317 \\
\hline \multicolumn{3}{|l|}{ Tanılar, n (\%) } & \\
\hline -Akut bronşit & $29(78,37)$ & $8(21,63)$ & \multirow{4}{*}{0,063} \\
\hline -İdiyopatik hemoptizi & $17(77,27)$ & $5(22,73)$ & \\
\hline •Pnömon & $16(76,19)$ & $5(23,81)$ & \\
\hline •Diğer & $10(47,61)$ & $11(52,39)$ & \\
\hline $\begin{array}{l}\text { Radyolojik bulgu } \\
\text { varlığı, } \mathrm{n}(\%)\end{array}$ & $27(37,50)$ & $16(55,20)$ & 0,104 \\
\hline
\end{tabular}

Hemoptizi nedenli Acil poliklinik başvurularının \%37,93’ü ( $n=11)$, Göğüs Hastalıkları poliklinik başvurularının \%8,33'ü $(n=6)$ hastaneye yatırılarak tedavi edilmiş olup, aradaki fark istatistiksel olarak anlamlı idi; $\mathrm{p}<0,001$ (Tablo 4). Hastalar hemoptizi şiddeti açısından değerlendirildiğinde 99 hastada minör hemoptizi gözlenmiş olup, 2 hastada masif hemoptizi görülmüştür. Masif hemoptizi görülen hastaların tanıları pnömoni ve bronşektazi idi. Acil polikliniğinde değerlendirilen ve hastane yatışı verilen 2 hasta ölmüştür. Bu hastaların tanıları akciğer kanseri ( akciğer kanseri ve solunum yetmezliği nedenli ölmüştür) ve pnömoni ( pnömoni ve solunum yetmezliği nedenli ölmüştür) idi. Hastaların başvuru polikliniği ile mortalite arasındaki ilişki değerlendirildiğinde, aradaki fark istatistiksel olarak anlamlı bulanmamıştır; p=0,080 ( Tablo 5).

\begin{tabular}{|l|c|c|c|c|}
\hline \multicolumn{3}{|c|}{ Tablo 4. Başvuru polikliniği ve hastane yatışı arasındaki ilişki } \\
\hline \multicolumn{2}{|c|}{} & \multicolumn{2}{|c|}{ Başvurduğu poliklinik } & \multirow{2}{*}{ Total } \\
\cline { 3 - 5 } & $\begin{array}{c}\text { Göğüs } \\
\text { Hast. }\end{array}$ & Acil & \\
\hline \multirow{3}{*}{$\begin{array}{l}\text { Hastane } \\
\text { yatış1 }\end{array}$} & Yapılan & $\begin{array}{c}6 \\
\% 8,33\end{array}$ & $\begin{array}{c}11 \\
\% 37,93\end{array}$ & $\begin{array}{c}17 \\
\% 16,83\end{array}$ \\
\cline { 3 - 5 } & Yapılmayan & $\begin{array}{c}66 \\
\% 91,67\end{array}$ & $\begin{array}{c}18 \\
\% 62,07\end{array}$ & $\begin{array}{c}84 \\
\% 83,17\end{array}$ \\
\hline \multirow{2}{*}{ Toplam } & & $\begin{array}{c}72 \\
\% 100\end{array}$ & $\begin{array}{c}29 \\
\% 100\end{array}$ & $\begin{array}{c}101 \\
\% 100\end{array}$ \\
\hline
\end{tabular}

Tablo 5. Başvuru polikliniği ve mortalite arasındaki ilişki

\begin{tabular}{|l|c|c|c|c|}
\hline \multicolumn{2}{|c|}{} & \multicolumn{2}{|c|}{ Başvurduğu poliklinik } & \multirow{2}{*}{ Total } \\
\cline { 3 - 4 } & $\begin{array}{c}\text { Göğüs } \\
\text { Hast. }\end{array}$ & Acil & \\
\hline \multirow{3}{*}{ Mortalite } & Yaşayan & $\begin{array}{c}72 \\
\% 100\end{array}$ & $\begin{array}{c}27 \\
\% 93,10\end{array}$ & $\begin{array}{c}99 \\
\% 98,01\end{array}$ \\
\cline { 2 - 4 } & \multirow{2}{*}{ Ölü } & $\begin{array}{c}0 \\
\% 0,0\end{array}$ & $\begin{array}{c}2 \\
\% 6,90\end{array}$ & $\begin{array}{c}2 \\
\% 1,99\end{array}$ \\
\hline \multirow{2}{*}{ Toplam } & & $\begin{array}{c}72 \\
\% 100\end{array}$ & $\begin{array}{c}29 \\
\% 100\end{array}$ & $\begin{array}{c}101 \\
\% 100\end{array}$ \\
\hline
\end{tabular}

Her iki bölüm başvurusu için cinsiyet ve öncesinde kronik akciğer hastalığı öyküsü varlığı arasında istatistiksel olarak anlamlı fark saptanmadı. Gögüs Hastalıkları polikliniğine başvuran hastalarda akut bronşit, idiyopatik hemoptizi ve pnömoni daha sık izlenirken, Acil polikliniği başvurularında bronşektazi ve pulmoner tromboemboli tanılarının daha sık izlendiği görüldü. Radyolojik bulgu varlığı, Acil polikliniğine başvuran hastalarda Göğüs Hastalıkları polikliniğine başvuran hastalara göre daha çok gözlenirken (sırasıyla; \%55,20 ve \%37,50, p>0,05) aradaki fark istatistiksel olarak anlamlı bulunmamıştır.

\section{TARTIŞMA}

Hemoptizi; hastaların ivedilikle hekime başvurmalarına sebep olan, solunum yolları hastalıklarının önemli semptomlarından biridir. Göğüs hastalıkları polikliniklerine başvuran hastaların \%6-8'inden hemoptizi sorumlu tutulmaktadir. $^{2}$

Lee BR ve ark.nın çalışmasında 221 hastanın (145'i erkek, 76 'sı kadın) yaş ortalaması $57 \pm 15$ yıldır. ${ }^{11}$ Doğan ve ark. 
nın yaptığı bir çalışmada yaş ortalaması $53 \pm 12$ yıl olarak saptanmış, hastaların \%73'ü erkek, \%27'si kadın ve hastaların çoğu 40 yaş üzerinde bulunmuştur. ${ }^{12}$ Özgül ve ark. nın yaptığı diğer bir çalışmada ise hemoptizi nedeni ile tetkik edilen 203 hastanın yaş ortalamasının 45,50 olduğu ve \%89,20'sinin erkek, \%10,80'inin kadın olduğu saptanmıştır. ${ }^{13}$ Bizim çalışmamızda hastalarımızın yaş ortalaması 51 (IQR 34-64) olup, cinsiyet dağılımına bakıldığında \% 49,50'si erkek, \% 50,50’sinin kadın olduğu gözlenmiştir. Literatürdeki çalışmalarda sadece Acil poliklinik başvurularının ya da sadece hastane yatışı verilen vakaların değerlendirildiği gözlemlenmiş olup, çalışmamızdaki cinsiyet dağılımın farklı olmasının nedeni çalışma dizaynının (Gögüs hastalıkları polikliniği ve Acil polikliniği hemoptizi başvuruları) farklılığına bağlanmıştır.

Tanısal değerlendirme amaçlı yaygın olarak; akciğer grafisi, toraksın BT ve fiberoptik bronkoskopi kullanılmaktadır. ${ }^{12,14-16}$ Hastaların \%7-34'ünde çok dikkatli bir çalışmaya rağmen hemoptizi sebebi tanımlanamamaktadır. ${ }^{10}$ Özgül ve ark.nın standart akciğer grafisi ile BT bulgularını birlikte değerlendirdikleri çalışmada kavite (\%22,70), yamalı infiltrasyon $(\% 15,80)$, kitle $(\% 15,30)$, konsolidasyon $(\% 8,90)$ oranında tespit edilmiştir. ${ }^{13}$ İntepe ve ark.nın çalışmasında akciğer grafilerinde en sık görülen patolojik bulgular infiltrasyon (\%48), bronşektazi (\%19,20), kitle $(\% 15,30)$ olarak saptanmış olup, toraks BT incelemelerinde ise en s1k infiltrasyon $(\% 23,80)$, fibrozis $(\% 18,70)$, kistik lezyon $(\% 16,30)$ saptanmıştır. ${ }^{17}$ Çalışmamızda radyolojik bulgular değerlendirildiğinde akciğer grafilerinde en sık gözlenen patolojik bulgular infiltrasyon $(\% 22,77)$, KOAH $(\% 7,92)$ ve bronşektazi $(\% 6,93)$ olarak saptanmış olup toraks BT'lerinde en sık gözlenen patolojik bulgular infiltrasyon (\%21,73), bronşektazi (\%10.14) ve pulmoner tromboemboli (\%8.69) idi.

Hemoptizinin etiyolojik nedenlerine bakıldığında akciğerin enfeksiyöz hastalıkları grubunun yıllar boyunca çeşitli serilerde hep birinci sıradaki neden olduğu; ancak etiyolojik nedenin yıllar içerisinde değişiklik gösterdiği görül- mektedir. Geçtiğimiz yüzyılda 90'lı yılların sonuna kadar hemoptizinin en sık karşılaşılan nedeni tüm dünyada tüberküloz iken günümüzde başarılı veremle mücadele yöntemleri ile tüberküloz alt sıralara gerilemiştir. ${ }^{18-20} 2000$ 'li yıllardan sonraki birçok seride hemoptizinin en sık nedeni bronşektazidir. Lee ve ark. ile Joughon ve ark.nın çalışmalarında bronşektazinin birinci sıradaki etiyolojik sebep olduğu; bunu malignitelerin izlediği bildirilmiştir. ${ }^{21,22}$ Nawal ve ark.nın çalışmasında hemoptizinin en sık nedeni bronşektazi $(\% 34,50)$ olarak saptanmıştır. ${ }^{23}$

Ülkemizde bronşektazi, bronş karsinomu ve tüberkülozun hemoptizinin en sik saptanan nedenleri olduğu bildirilmiştir. ${ }^{12,24-26}$ İntepe ve ark.nın çalışmasında hemoptizi nedenlerine bakıldığında ilk üç sırayı bronşektazi, akciğer kanseri ve idiyopatik hemoptizinin oluşturduğu görülmüştür. ${ }^{17}$ Ancak yapılan farklı bir çalışmada hemoptizi etiyolojisinde günümüzde kısmen değiștiği ve bronşektazi ile tüberküloza bağlı hemoptizilerin azalmasına karşın bronşite bağlı hemoptizilerin arttığı bildirilmiştir. ${ }^{26}$ Bazı gelişmiş ülkelerden bildirilen çalışmalarda etiyolojide bronşitin ilk sıralarda yer alması dikkat çekicidir. ${ }^{27,28}$ Japonya' da 80 hasta ile yapılan bir çalışmada hemoptizi nedenleri incelendiğinde; en sık olarak bronşit \%27, bronşektazi \%19 ve enfeksiyon \%14 oranında saptanmıştır. ${ }^{27}$ Bizim çalışmamızda bölgemizde hemoptizi ile başvuran 101 hastada en sık akut bronşit $(\% 36,63)$, idiyopatik hemoptizi $(\% 21,78)$, pnömoni $(\% 20,79)$ ve bronşektazi $(\% 6,93)$ hemoptizi nedeni olarak saptanmıştır.

Sonuç olarak, hemoptizi değişik etiyolojik faktörlerle oluşabilen önemli bir pulmoner semptomdur. İkinci basamak sağlık kuruluşlarına hemoptizi yakınması ile ayaktan başvurularda olguların yarısından fazlasını enfeksiyöz nedenler ve idiyopatik hemoptizi oluşturmaktadır. Zaman içerisinde koruyucu hekimliğin gelişmesi, tanı ve tedavi sürecinde yaşanan ilerlemeler hemoptizi etiyolojisinde yer alan hastalıkların sıklığında değişikliğe yol açmakta ve daha benign hastalıklara bağlı oluşan hemoptizileri ön plana çıkartmaktadır. 
Sakarya Tip Dergisi 2019;9(4):626-631

ÇOLAK ve Ark., Hemoptizi Yakınması ile Başvuran Hastalarda Etyolojik Değerlendirme

Kaynaklar

1. .Jeudy J, Khan AR, Mohammed TL, et al: ACR. Appropriateness Criteria hemoptysis. J Thorac Imaging 2010; 25:67-69.

2. Özlu T. Massif hemoptizi. İ̧̧inde: Ekim N, Turktaş H, editör. Goğüs hastalıkları acilleri. 1. Baskl. Ankara: Bilimsel Tip Yayinevi; 2000. s.241-246.

3. Hirsberg B, Biran I, Glazer M, et al: Hemoptysis: etiology, evaluation, and outcome in a tertiary referral hospital.Chest 1997; 112(2):440-444.

4. Corey R, Hla KM. Major and massive hemoptysis: reassessment of conservative management. Am J Med Sci 1987; 294(5):301-309.

5. Patel SR. Stoller JK: The role of bronchoscopy in hemoptysis. In: Wang K, Mehta AC (eds). Flexible Bronchoscopy. Cambridge: Blackwell Science, 1995: p.298-321.

6. Lordan JL, Gascoigne A, Corris PA. The pulmonary physician in criticalcare. Illustrative case 7: Assessment and management of massive hemoptysis. Thorax 2003; 58(9):814-819.

7. Weinberger SE, Braunwald E. Cough and hemoptysis. In: Braunwald E, Fauci AS, Kasper DL, Hauser SL, Longo DL, Jameson JL (eds). Harrison's Principles of Internal Medicine, 15 thed. New York: McGraw-Hill. 2001: p.203-206.

8. Reisz G, Stevens D, Boutwell C, et al: The causes of hemoptysis revisited. A review of the etiologies of hemoptysis between 1986 and 1995. MoMed 1997; 94:633-637.

9. Santiago S, Tobias J, Williams AJ. A reappraisal of the causes of hemoptysis. Arch Intern Med 1991; 151(12):2449-2451

10. Herth F, Ernst A, Becker HD. Long-term outcome and lung cancer incidence in patients with hemoptysis of unknown origin. Chest 2001; 120(5):1592-1594.

11. Lee BR, Yu JY, Ban HJ, et al. Analysis of patients with hemoptysis in a tertiary referral hospital. Tuberc Respir Dis (Seoul) 2012; 73(2):107-114.

12. Doğan ÖT, Berk S, Engin A, Akkurt İ. Hemoptizide etiyolojk faktörler. Cumhuriyet Tip Dergisi 2010; 32:48-53

13. Özgül MA, Turna A, Yildız P, Ertan E, Kahraman S, Yilmaz V. Risk factors and recurrence patterns in 203 patients with hemoptysis Tüberküloz ve Toraks Dergisi 2006; 54(3): 243248 .

14. McGuinness G, Beacher JR, Harkin TJ, Garay SM, Rom WN, Naidich DP. Hemoptysis: prospective high-resolution CT/bronchoscopic correlation. Chest 1994; 105(4):1155-1162.

15. Set PA, Flower CD, Smith IE, Chan AP, Twentyman OP, Shneerson JM. Hemoptysis: comparative study of the role of CT and fiberoptic bronchoscopy. Radiology 1993; 189(3):677-680.
16. Yoon W, Kim JK, Kim YH, Chung TW, Kang HK. Bronchial and nonbronchial systemic artery embolization for life threatening hemoptysis: a comprehensive review. Radiographics 2002; 22(6):1395-1409.

17. İntepe Y.S, Aydın Y. Hemoptizi: Tanısal yöntemlerin karșılaştırılması ve Akciğer Kanseri için risk faktörlerinin belirlenmesi. Bozok Tip Dergisi 2016; 6(2):38-47.

18. Garzon AA, Gourin A. Surgical management of massive hemoptysis. A ten-year experience. Ann Surg. 1978; 187(3):267-271.

19. Conlan AA, Hurwitz SS, Krige L, Nicolaou N, Pool R. Massive hemoptysis. Review of 123 cases. J Thorac Cardiovasc Surg. 1983; 85(1):120-124.

20. Knott-Craig CJ, Oostruizen JG, Rossouw G, Joubert JR, Barnard PM. Management and prognosis of massive hemoptysis. Recent experience with 120 patients. J Thorac Cardiovasc Surg. 1993; 105(3):394-397.

21. Lee TW, Wan S, Choy DK, Chan M, Arifi A, Yim AP. Management of massive hemoptysis: a single institution experience. Ann Thorac Cardiovasc Surg. 2000; 6(4):232-235.

22. Jougon J, Ballester M, Delcambre F, et al: Massive hemoptysis: what place for medical and surgical treatment. Eur J Cardiothorac Surg. 2002; 22(3):345-351.

23. Unsal E, Köksal D, Çimen F, Hoca NT, Şipit T. Analysis of patients with hemoptysis in a reference hospital for chest diseases. Tüberküloz ve Toraks Dergisi 2006; 54(1):34-42.

24. Çelik P, Gönlügür U, Akın M, Orman A. "Hemoptizili Olgularımızın Analizi".Heybeliada Tip Bülteni Ocak 1997; 3:45-48.

25. Nawal SK, Heda MR. Hemoptysis: A prospective analysis of 110 cases. Asian J Biomed Pharm Sci 2013; 3:1-3.

26. Șenyiğit A, Bayram H, Asan E, Bukte Y, Topçu F. “Akciğer Radyografisi Normal Saptanan Hemoptizili Olgularda Fiberoptik Bronkoskopi ve Yüksek Rezolüsyonlu Bilgisayarl Tomografinin Tanıdaki Değeri”. Solunum Hastalikları 2001; 12:123-128.

27. Tsoumakidou M, Chrysofakis G, Tsiligianni I, Maltezakis G, Siafakas NM, Tzanakis N. Prospective Analysis of 184 Hemoptysis Cases - Diagnostic Impact of Chest X-Ray, Computed Tomography, Bronchoscophy. Respiration 2006; 73(6):808-814.

28. Seki N, Shiozaki G, Ota M. Risk Factors for a Second Episode of Hemoptysis. Clinical Me dicine: Circulatory Respiratory and Pulmonary Medicine 2009; 3:1-7. 